\title{
Practice Learning for Occupational Therapy in a Time of the Global COVID 19 Pandemic
}

\author{
*Thavanesi Gurayah ${ }^{a}$ \\ a: University of KwaZulu Natal, South Africa
}

\section{Background}

Fieldwork modules in the discipline of Occupational Therapy at the University of KwaZulu Natal in South Africa typically run for a semester for second and third year modules. However, fieldwork continues throughout the year for fourth year modules, and students are required to complete four blocks of around seven weeks each for the paediatrics, physical rehabilitation, psychosocial and community practice modules (University of KwaZulu Natal: College of Health Sciences, 2020). The learning objectives of these components are required to hone the students' clinical skills and develop the professional behaviours required of an occupational therapist.

\section{Assessment}

The assessment components on the fieldwork modules consists of the students' clinical performance on key domains such as assessment, treatment and professional behaviours, a case presentation, case study report, and an assessment or a treatment demonstration, which all contribute to the final mark in different weightings (University of KwaZulu Natal: College of Health Sciences, 2020). The case presentation is done with the supervisor and other students in the group, which allows for peer learning (Stone et al., 2013). Students are able to learn vicariously how to extract and present the most relevant information for the 22 minute time allocation, which benefits weaker students.

In occupational therapy, the learning objectives of the theory and fieldwork modules provide students with the theory, principles, and practice of assessment and treatment with regards to the psychosocial field of practice (University of KwaZulu Natal: College of Health Sciences, 2020). It allows the students to assess and treat individuals, as well as groups of individuals. While the focus is on assessment for second year students, in the third year, the focus moves to treatment, and the theory and application of different approaches to intervention, with regards to different psychosocial conditions, age groups and stages of recovery (University of KwaZulu Natal: College of Health Sciences, 2020). In the fourth and final year of study, occupational therapy students are expected to work more independently, and perform assessments and treatments comprehensively and expediently. They are also expected to have the requisite knowledge and skills to practice in diverse mental health care settings.

*Corresponding Author: Thavanesi Gurayah, University of KwaZulu-Natal, Durban, 4041 South Africa.

Email: Gurayaht@ukzn.ac.za

Journal URL: https://publications.coventry.ac.uk/index.php/pblh

Gurayah, T. (2021). Practice learning for occupational therapy in a time of the global COVID 19 pandemic. International Journal of Practice-based Learning in Health and Social Care, 9(2, 82-84, DOI 10.18552/ijpblhsc.v9i2.728 
During the pandemic, the case presentation and demonstration were undertaken using the online Zoom® platform, with the academic supervisor and peers. This required students to be au fait with Zoom technology, specifically how to send a Zoom invite, share a screen, and write a comment or question in the chat box (Concordia University: Centre for Teaching and Learning, 2020). Zoom etiquette also required all participants to mute their microphones, unless they were speaking, and switch off their videos, which consumed a large amount of data if used continuously. The university provided all students and staff with data during the pandemic to ensure teaching and learning was not compromised. Moreover, disadvantaged students were provided with laptops if they did not have access to an electronic device for online learning. There were instances however, which necessitated cameras to remain on, such as during a group session, individual treatment, or exam video. This allowed for some human connection in a socially distanced therapeutic space, and allowed observers to analyse the non-verbal behaviours of clients and students. However, having videos on could have inhibited student participants from sharing their personal information and feelings, especially the occupational therapy students, as I was an observer for the groups run by the fourth year students that I had supervised. Other aspects of online assessment required extensive support and training for staff and students who had to adapt to the virtual Moodle platform. Assistance entailed uploading learning content, setting up and marking online tests, and fielding queries from students.

\section{Impact of the pandemic}

The practice and form of service learning in occupational therapy was forced to drastically change during the global pandemic of 2020. Normally these are done at fieldwork sites, but when the coronavirus entered South Africa, it abruptly terminated that option. Fieldwork sites withdrew their permission for students to complete the fieldwork at their institutions, due to the need to protect their clients and residents, and contain new infections.

For second year students, some of the strategies used to teach and simulate clinical components included using case studies to provide students with information, which they had to use to compile a case presentation and case reports. Students were required to review two case studies, which gave them practice in the critical fieldwork components of compiling a case presentation and case report. Moreover, the first case study was used for formative assessment, and the second case was used for summative assessment. The case studies were extracted from student reports that had received high marks from the previous year. Once the assessments of the case presentation and case reports were done, a Zoom tutorial was scheduled to give the students detailed group feedback, in addition to the intensive individual feedback provided on the students' case reports and presentations. The full versions of the case report and case presentation were released to the students for their continued learning once the assessments were completed.

For third year students, the strategies used to accrue clinical hours were to divide the students into four groups. Two of the groups were sent to fieldwork sites, one group was designated the virtual or telehealth group, and the fourth group remained on campus to practice group work components. This was a fully supervised block, so all students were allocated a supervisor, and the numbers of the students per group were small, with approximately seven to eight students per group. The Telehealth Group had to run groups with second year occupational therapy students to offer psychosocial and academic support for online learning. SIMUCASE and Ice videos, which are online learning tools, were also used to access case studies for learning purposes for this group.

Fourth year students on the psychosocial module accrued their clinical hours from Telehealth sessions, and webinars on topics such as Autism, Bereavement and Grief Counselling. These webinars were done to support non-governmental organizations such as Autism in Action, and the South African Depression and Anxiety Support Group. Students were fully supervised and involved in all aspects of these webinars from developing the content, sending out the invites and hosting the webinars.

\section{Reflections}

The optimum and preferred mode of fieldwork practice for health science students remains the real world situation of hospitals, rehabilitation centres, clinics, community settings and residential living facilities. 
However, during the global coronavirus pandemic, occupational therapy programmes worldwide, had to dig deep and provide relevant, simulated or online service learning opportunities. I found identifying and providing relevant learning opportunities for students on the second year psychosocial module extremely stressful. The team had to brainstorm ideas for practice learning, and some universities collaborated to share ideas and resources. As students acclimatized to the technology and tools, this online telehealth therapy became a viable option to deliver occupational therapy services, especially sessions around stress management, time management, relaxation therapy, and providing psycho-didactic and psychosocial support to students and other mental health care users.

Students and staff showed flexibility and resilience in adapting as they went along this unchartered route in practice learning, for which there was no road map on how to negotiate online and blended learning for occupational therapy students. Some of the lessons learned were that staff and students must become aufait with the specific technologies required, such as Zoom or Google Meet ${ }^{\circledR}$, and preferably have their own devices and sufficient data. In South Africa, this was a challenge for some students, especially those reliant on state funding from the National Student Financial Aid Scheme (NSFAS). Going forward, most programmes will most likely embrace a blended approach for health science education, to ensure continued learning during pandemics or other unforeseen circumstances when face to face learning is not possible. This comes with advantages and disadvantages, including a blurring of work hours, greater flexibility for students and staff regarding supervision times, an increased diversity of service learning sites, decreased costs of health science programmes, and greater accommodation for increased student intakes. For health science education, it also requires a paradigm shift that not all learning has to be contact learning, and will ensure that future health science professionals are self-regulated life-long learners fit for purpose in an increasingly digital world.

\section{Acknowledgements}

I would like to acknowledge Julie Lingah and Debbie Fewster, my colleagues at UKZN who worked with me on the psychosocial modules at UKZN.

\section{ORCID}

Thavanesi Gurayah - https://orcid.org/0000-0001-9005-6355

\section{References}

Concordia University: Centre for Teaching and Learning. (2020). Zoom etiquette for students. https://www.concordia.ca/ctl/students/zoom-etiquette.html

Stone, R., Cooper, S., \& Cant, R. (2013). The value of peer learning in undergraduate nursing education: A systematic review. International Scholarly Research Notices. Article 930901. https://doi.org/10.1155/2013/930901

University of KwaZulu Natal: College of Health Sciences. (2020). Handbook. College of Health Sciences. http://saa.ukzn.ac.za/Libraries/Hand_Books_2018/CHS_2020.sflb.ashx 